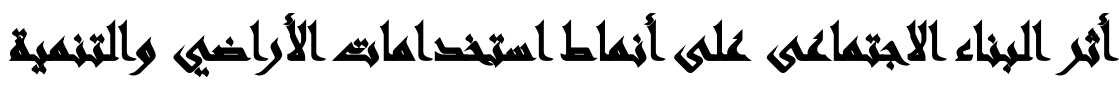

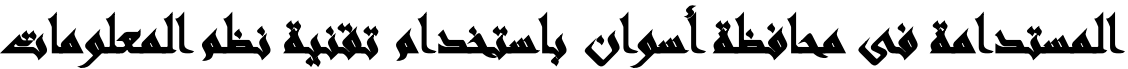

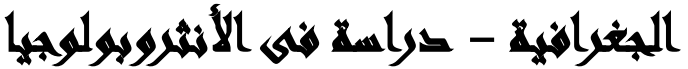

[9]

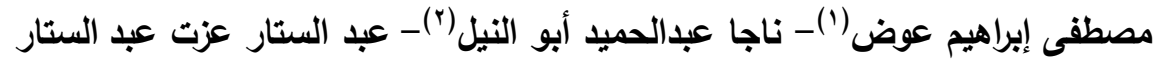

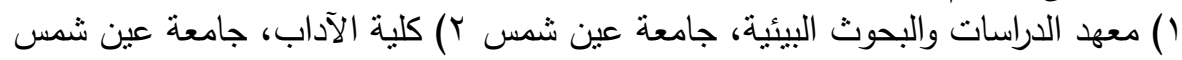

\section{المستخلس}

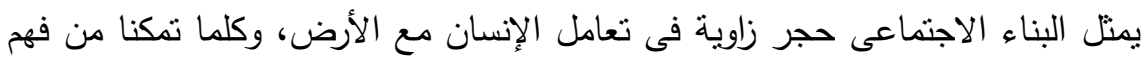

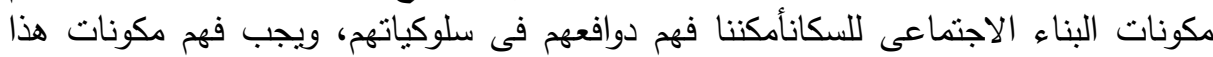

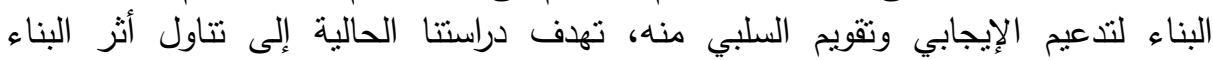

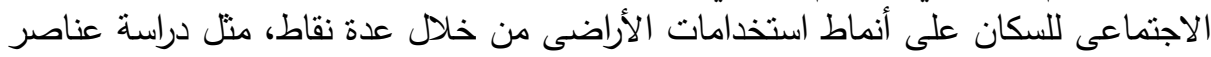

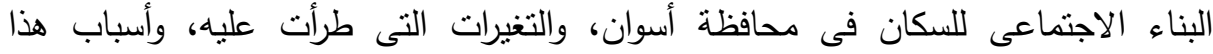

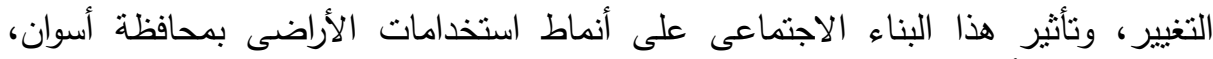

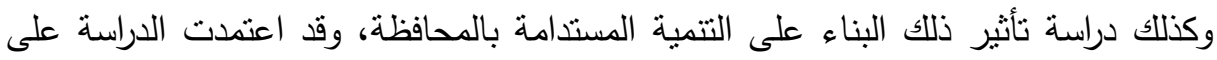

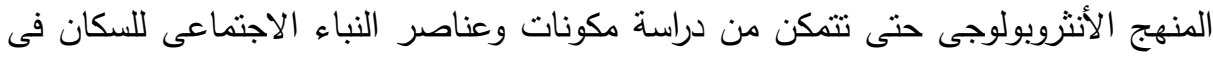

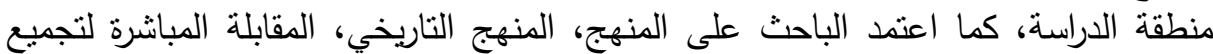
البيانات والمعلومات اللازمة لداستة الداسته.

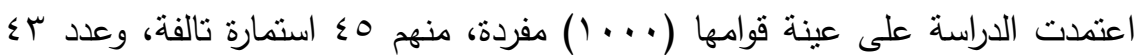

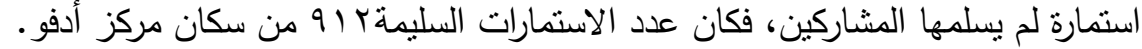

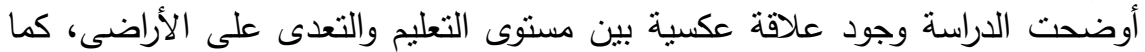

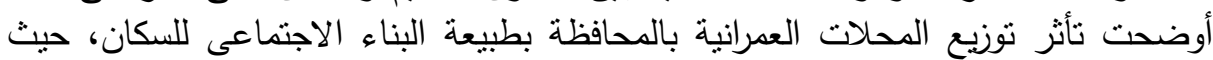

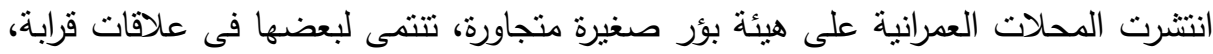

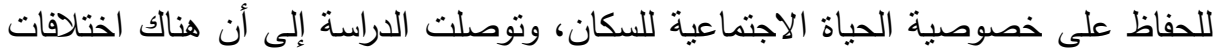

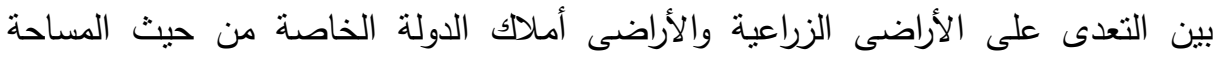

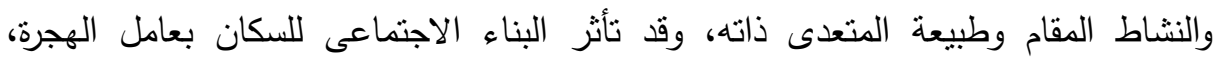

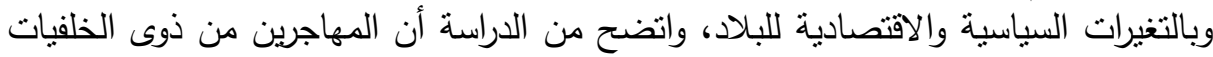

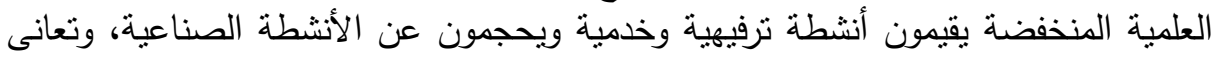

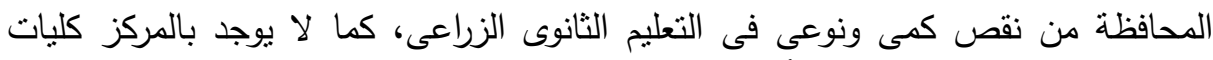

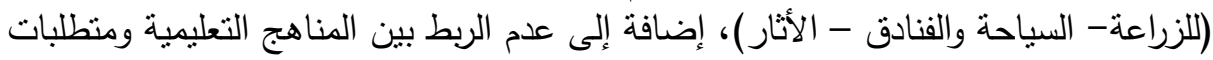

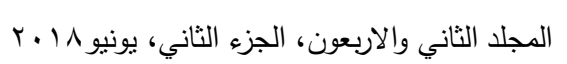


سوق العمل، وبناء على ما استتنجه الدراسة وما توصلت إليه، عرضت الدراسة توصبات منها: • إعداد ونشر برامج للتوعية بأهمية الحفاظ على الأراضى من التعدى، وتأثثر ذلك على • تأسيس كليات(للسياحة والفنادق- للآثار - للزراعة)، والاهتمام بنشر وتطوير المدارس الفنية لا سيما الزراعية. تأسيس كيانات لنسويق المنتجات الزراعية للإستفادة من ميزة النضج المبكر للمحاصيل.

\section{Xas}

يولد الإنسان فى إطار بناء اجتماعى محدد الأنظمة والأنساق، يحكم أفكاره وعاداته

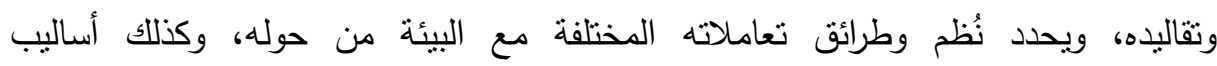

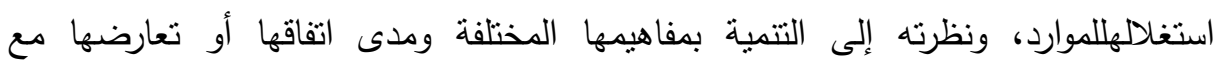

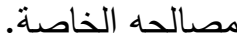
وتلعب التنشئة الاجتماعية دوراً مهماً فى توجيه قيم الأفراد، ويختلف تأثير البناء

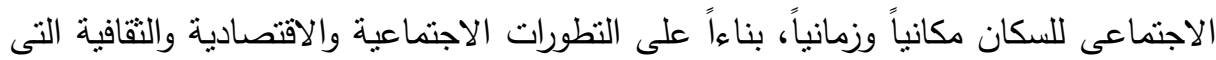

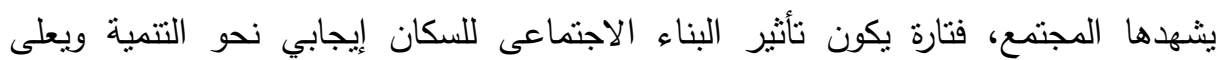

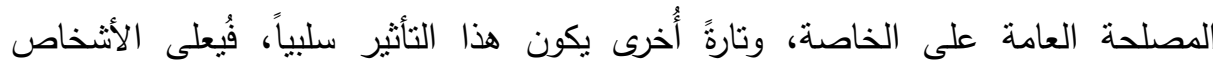
مصالحهم الخاصة على المصلحة العامة. وقد تأثرت استخدامات الأراضى بهذه التغيرات، فحينما كان المجتمع المصرى زراعى

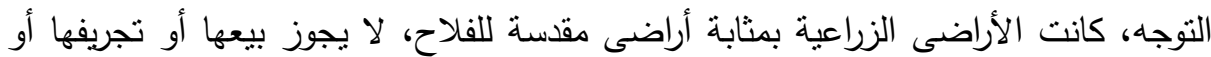
إهمالها، وعندما تأثرت الدولة بهجرات الثباب إلى دول النفط - وإغلبهر من أبناء الطبقة الوسطى التى كان لها ارتباط بالأرض- وبعد عودة المهاجرين بعاداتاستهلاكية فى المقام

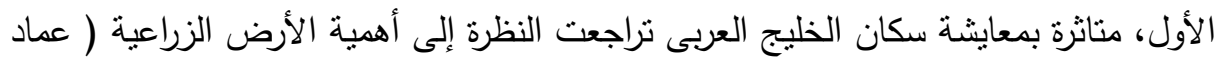

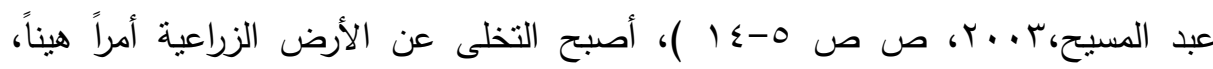

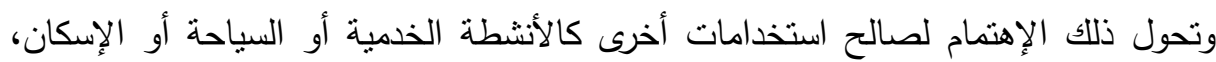

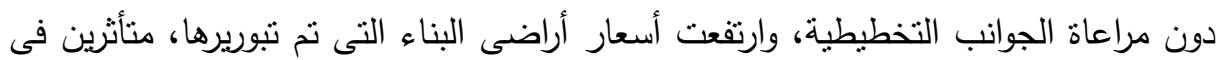

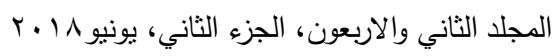


ذللك بنسق ثقافى يحتم الارتباط بالعائلة والإقامة فى نفس المكان، حتى لو على حساب أراضٍ

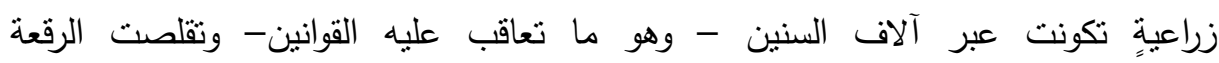

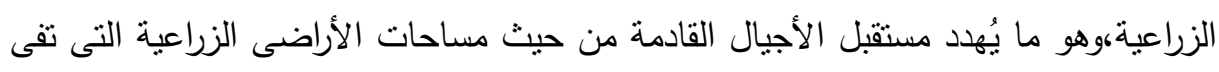

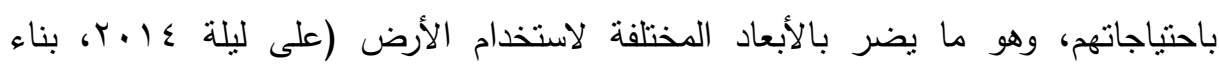

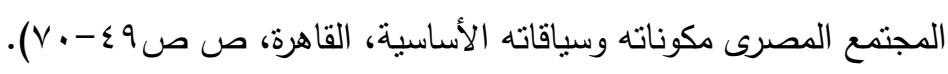

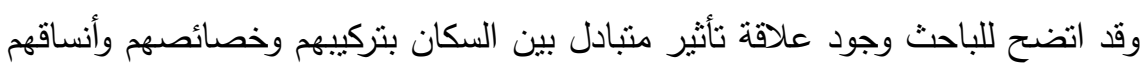

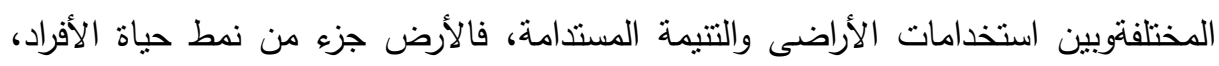
وتؤثر فى خططهم ونتأثز بأفكارهم واستخداماتهم لها.

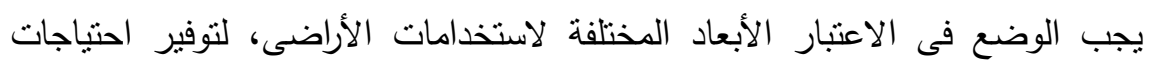

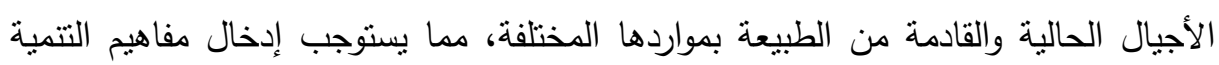

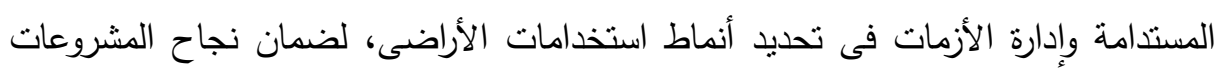

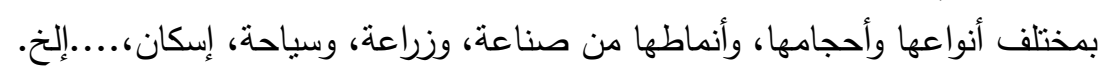

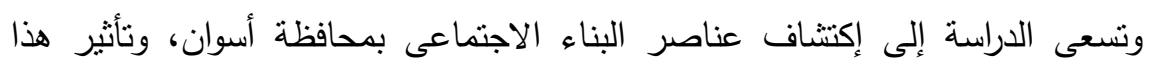

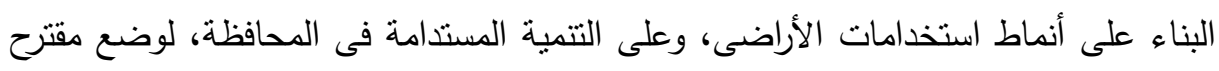

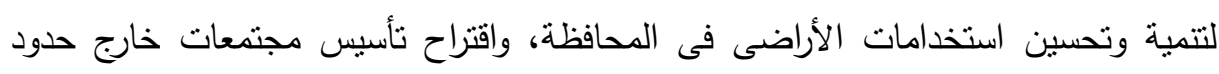
الوادى القديم، تخفيفاً للضغط على المرافق فى المدن القديمة، وبما يعود بالنفع على السكان.

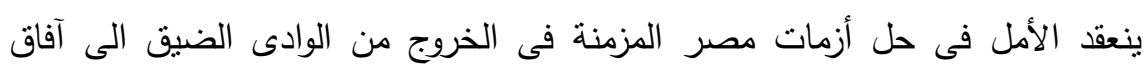

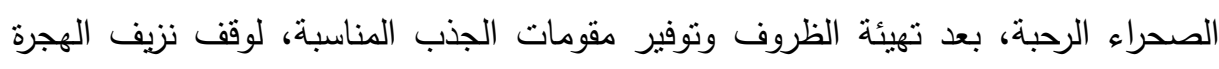

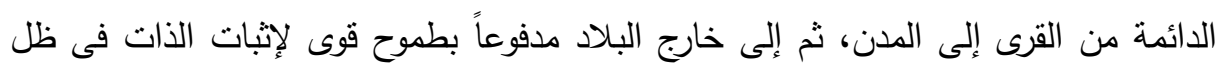
أزمة قلة فرص العمل بالبلاد وتراجع معدلات التنمية.

\section{منشحلة التراسمة}

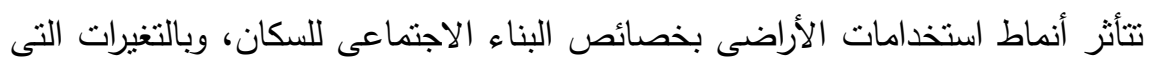

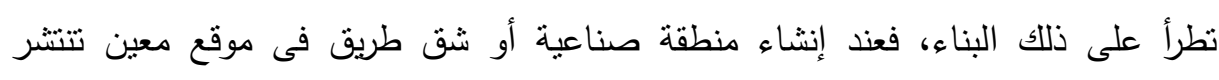

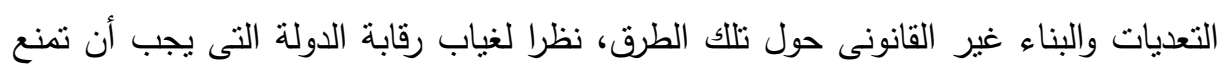

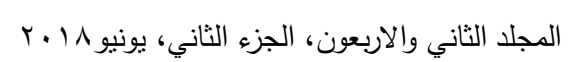




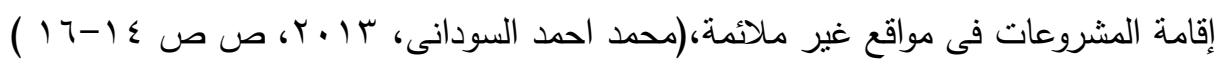
ويخلق كل ذلك وغيره مشكلات اجتماعية واقتصادية وبيئة.

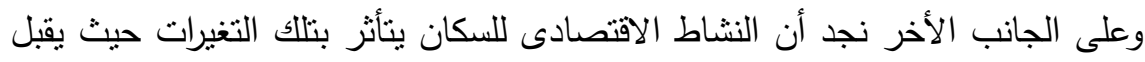

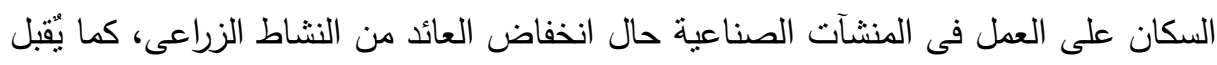

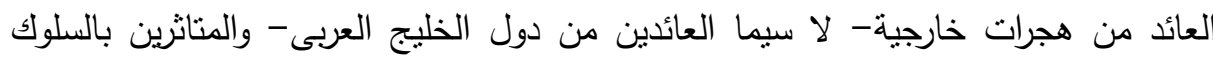
الاستهلاكى لسكان دول الخليج يقلون على اقامة مشروعات خدمية نرفيهية (سمير نعيم،

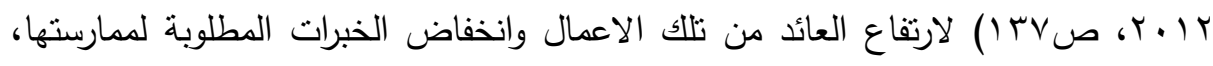
وبالتالى يتغير شكل البناء الاجتماعى للسكان بهذه المحلات العمرانية، وبذلك نلاحظ وجود تأثثر وتأثر بين نمط استخدامات الأراضى والبناء الاجتماعى للسكان، كما تتأثر خطط التنمية بخصائص البناء الاجتماعى للسكان.

\section{تتمثل مشكلة الاراسة فى عدة نقاط كما يلى}

1- تتكون محافظة أسوان من مجموعة من القبائل (عرب - نوبيين - صعايدة) (محمد

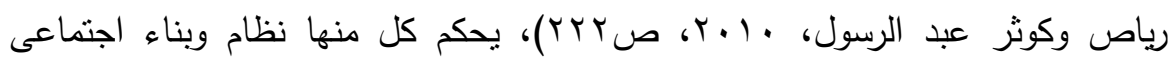
خاص. r-التأثثر الذى يحدثه البناء الاجتماعى للسكان بمختلف أنساقه على استخدامات الأراضى، وبالتالى على خطط التتمية. r-تؤثز الهجرة فى طبيعة البناء الاجتماعى للسكان وبالتالى فى استخدامات الأراضى. ع-يتاثز البناء الاجتماعى بالمستوى التعليمى للسكان وينعكس ذللك على استخداهتهم للأراضى . ه-ضعف معدلات التتمية فى الكثير من المدن والقرى المصرية بشكل عام وتأثير ذلك على لكراضى البناء الاجتماعى للسكان. 


\section{تساؤلايش السراسلة}

ا . ما عناصر البناء الاجتماعى للسكان فى محافظة أسوان؟

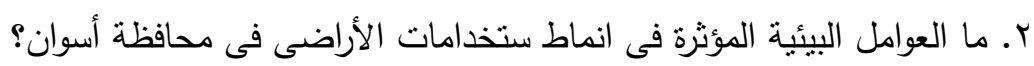
r. ما طبيعة العلاقة بين البناء الاجتماعى للسكان واستخدامات الأراضى فى محافظة أسطاط أسوان؟

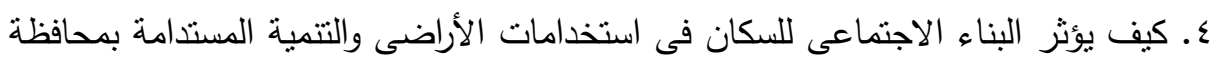

أسوان؟

ه. ما دور نظم المعلومات الجغرافية فى تحقيق التتمية المستدامة لأستخدامات الأراضى؟

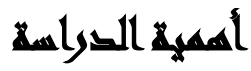

تتقسم أهمية الدراسة إلى شقين، الأول نظرى وبتمثل فى تزويد المكتبة العربية بدراسة

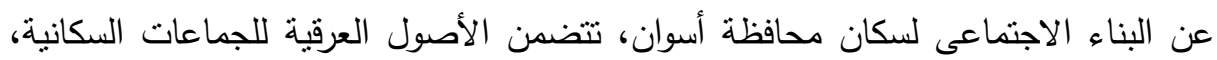

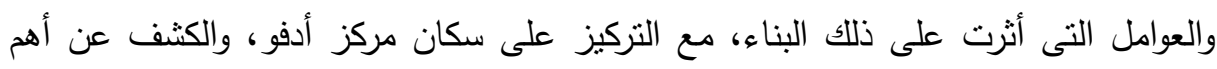

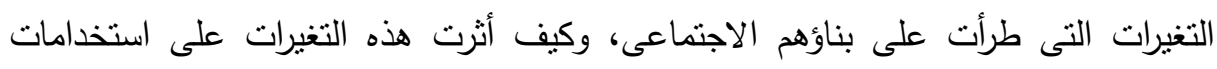

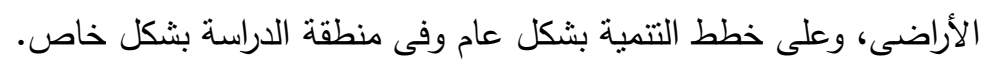

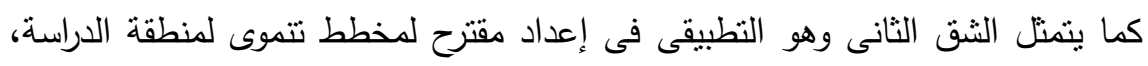
لمواجهة مشكلات استخدامات الأراضى ومواجهة ظاهرة التعدى علبها، وتتمية القدرات البشرية

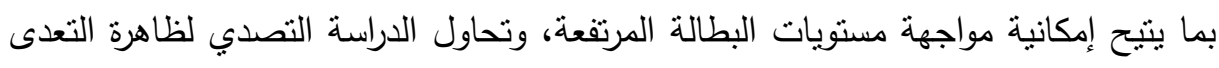

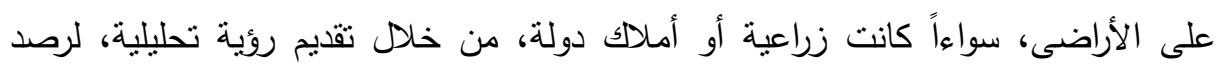

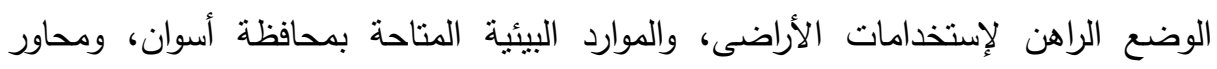
مواجهة التعدى على اراضى من الناحية التعليمية - الإعلامية - التتريعية - التتفيذية. كما تساعد الدراسة فى توضيح دور تطبيقات نظم المعلومات الجغرافية فى وضع خطط تتموية لإستخدامات الأراضى بمحافظة أسوان. 


\section{أهساهيم التراسما}

$$
\text { تهذف الدراسة إلى تناول عدة جوانب كما يلى: }
$$

• دراسة البناء الاجتماعى للسكان فى محافظة أسوان والتغيرات التى طرأت عليه بالمحافظة

$$
\text { وتأثيرها على أنماط استخدامات الأراضى بمحافظة أسوان. }
$$

• دراسة العلاقة المتبادلة بين البناء الاجتماعى للسكان واستخدامات الأراضى فى محافظة

• تحليل الوضع الراهن لاستخدامات الأراضى فى منطقة الدراسة من خلال تحليل البناء الاجتماعى للسكان فى منطقة الدراسة، وعلاقته بالنظم الاجتماعية والاقتصادية القائمة،

للوصول إلى أفضل أساليب التتمية المستدامة لاستخدامات الأراضى.

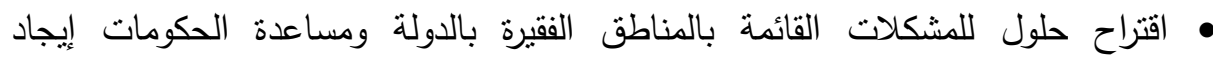

مشروعات قومية تحل مشكلات هؤلاء السكان فى كافة المجالات (الصناعة - الزراعة - بالهون

$$
\text { التعليم الجيد وربطها باحتياجات السوق المحلى .......الخ). }
$$

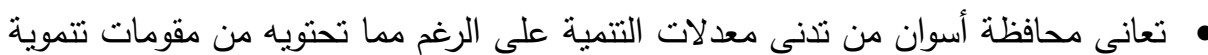

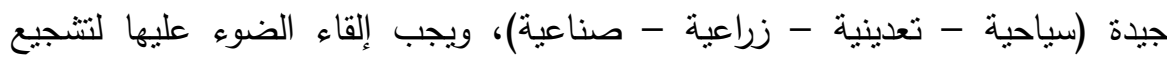

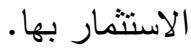

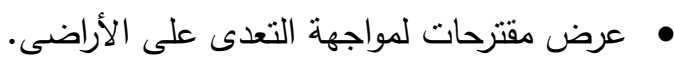

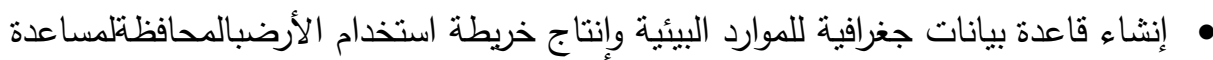

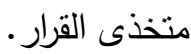
• وضع نموذج مقترح لتحقيق التنمية المستدامة فى محافظة أسوان.

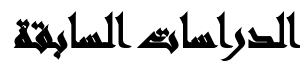

دراسات خاصة بالبناء الاجتماعى للسكان:

• محمد عبد الله البكر،2004م:" أثز البطاله على البناء الاجتماعى، مجلة العلوم

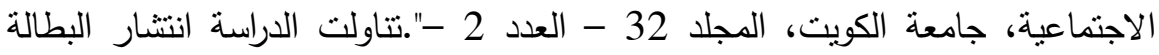

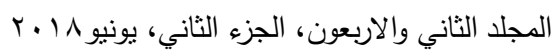


والجريمة بين السكان، لا سيما خاصة من ذوى المستويات التعليمية المنخفضة، مما

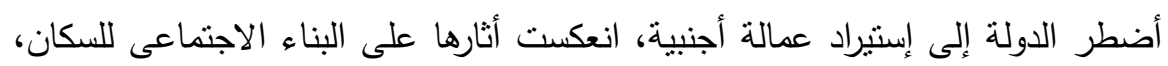

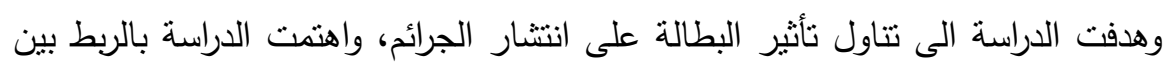

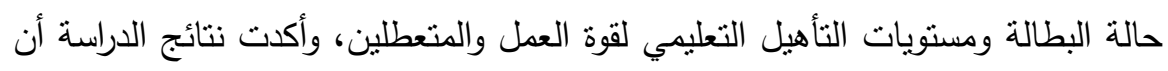
الحالة التعليمية للقوى العاملة تعد متغير أساسي يسهم في تفسير اختلاف حجم البطالة

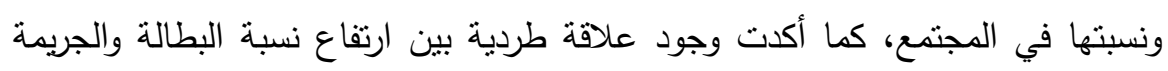

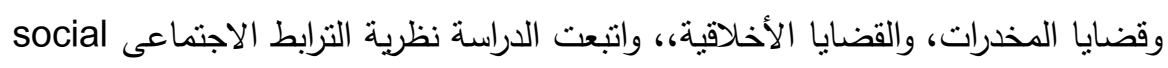
bond theory البناء الاجتماعى يؤثز على مستويات التعليم، وأن هناك علاقة عكسية بين مستويات

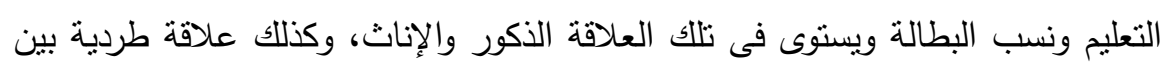

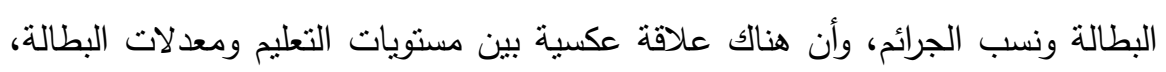
وأوصت الدراسة بضرورة الاهنمام بالتعليم لمواجهة انتشار الجرائم.

• حسين محمد صديق، 9 . . ب "أثر البناء الاجتماعي في مستويات الأداء في المؤسسات

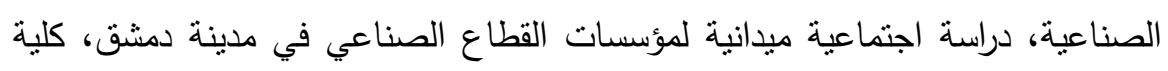

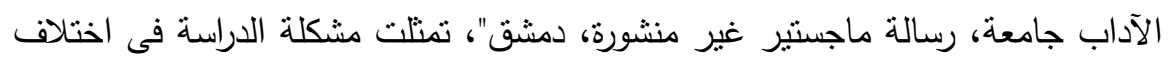

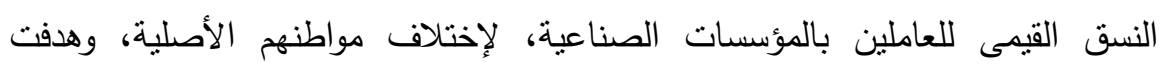

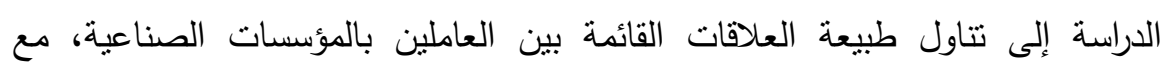

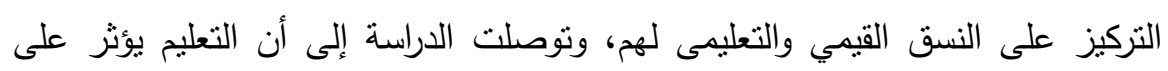

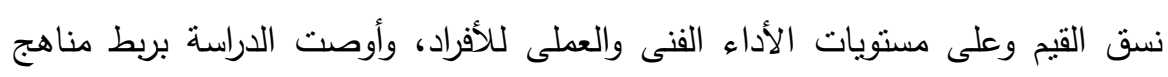

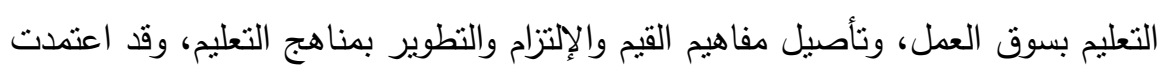

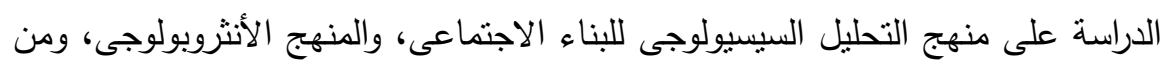

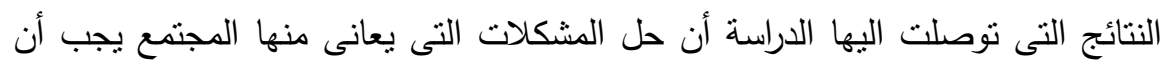

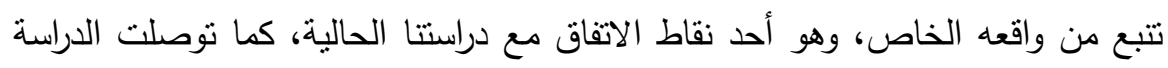

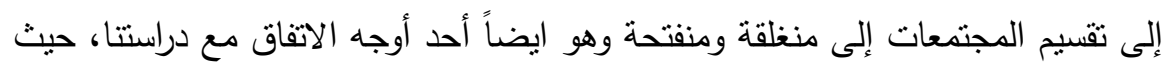
كانت مجتمعات النوبيين منغلقة قبل التهجير ، وأصبحت شبه منفتحة بعد التهات التهجير .

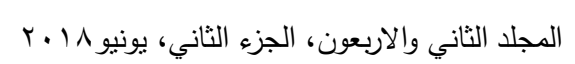


دراسات خاصة باستخدام الأرض:

• حسام محمد جاب الله، 1 ـ ـ ب: الأخطار الجيومورفولوجية الرئيسية في وادي النيل

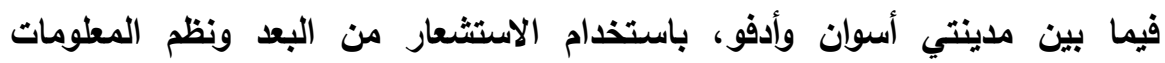

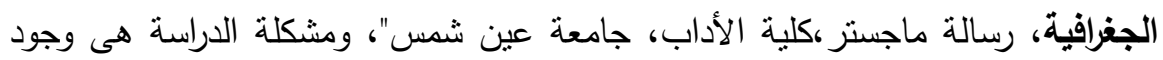
بعض الأخطار الجيومورفولوجية المحدقة بالمنطقة من مركز أدفو حتى مركز أسوان، الإنية

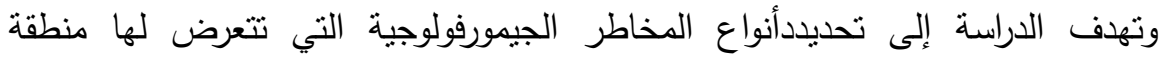

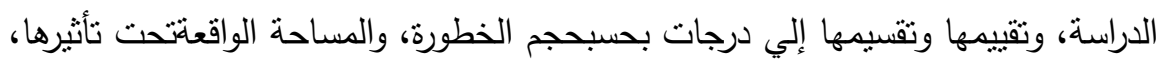

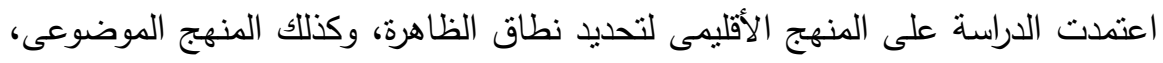

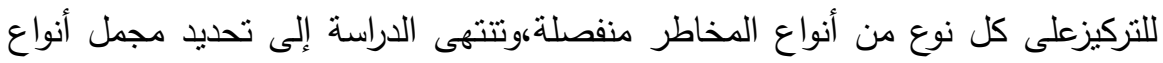

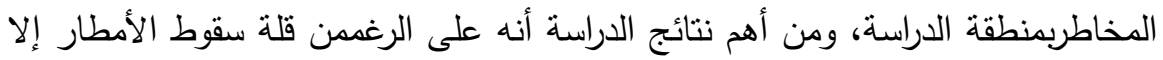

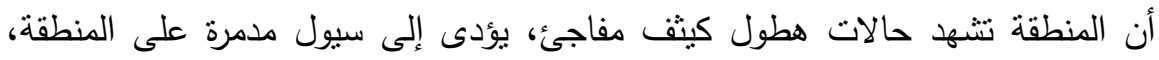

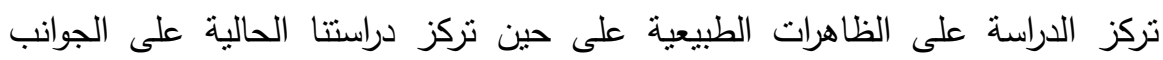
البثرية والعوامل المؤثرة فيها.

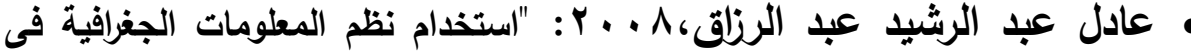

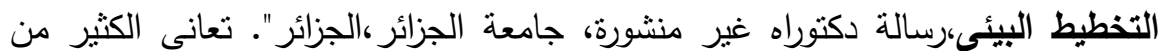

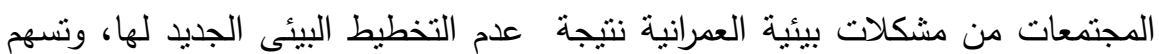

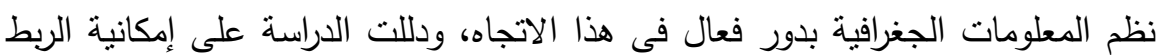
بين نظام التخطيط البيئي ونظام المعلومات الجغرافية، وأوضحت أهمية التخطيط البيئي

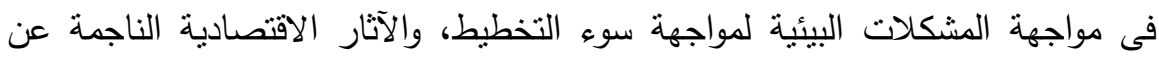
ذللك، وقد أوصت الدراسة بضرورة اعتبار دراسات نقييم الأثر البيئى معيارًا أساسياً الإسيا

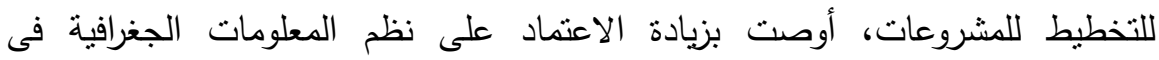

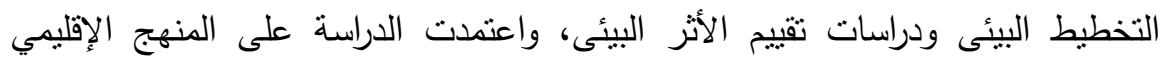

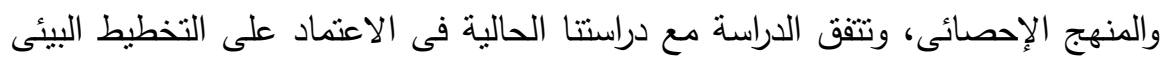

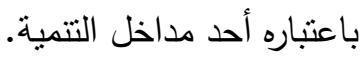




\section{• محمد سعيد عبدالمعطى 1 ا ـ ؟ "تطور استخدام الأراضى فى حى الزيتون}

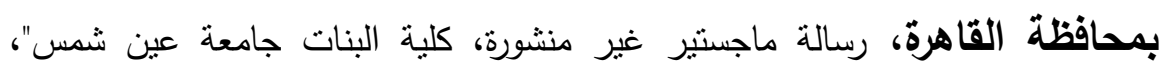
اهتمت الدراسة بمنابعتنطوراستخدام الرض بحى الزيتون خلال الفترة من عام 1947 حتى التى

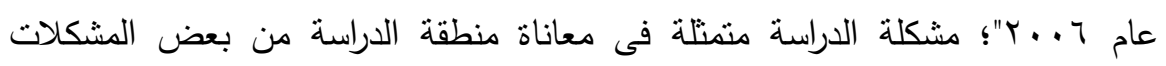

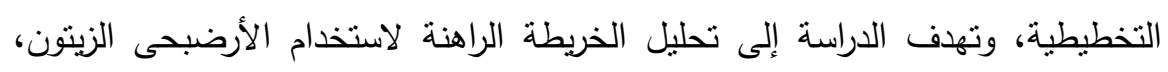

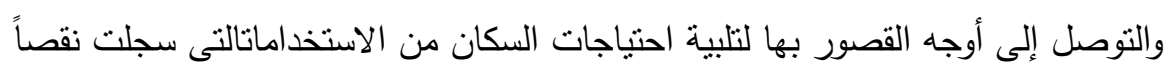

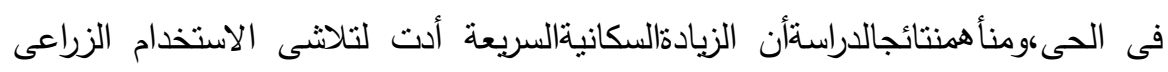

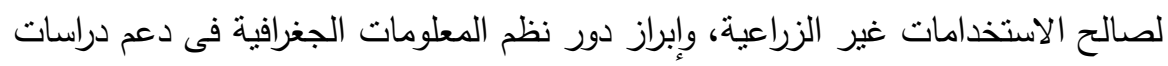

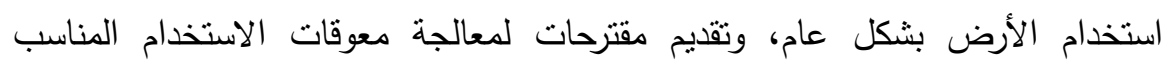

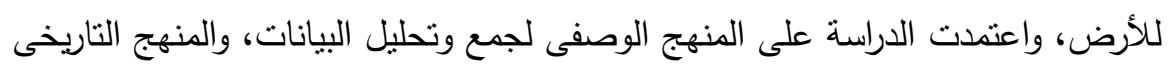

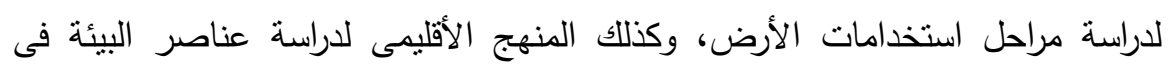

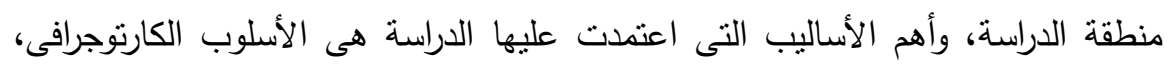

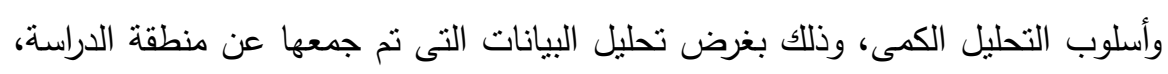

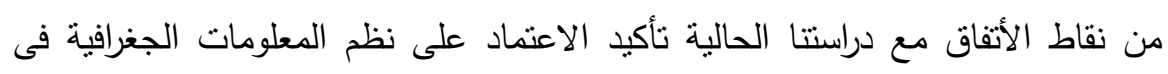

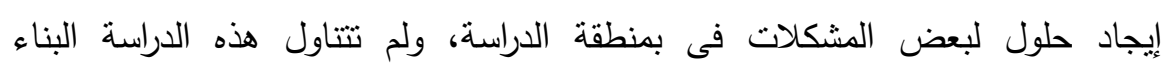

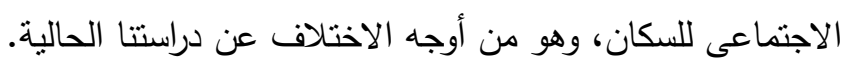

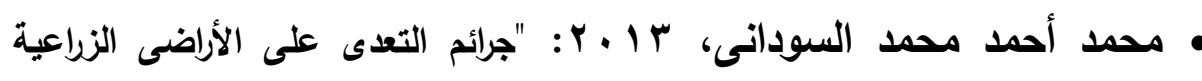

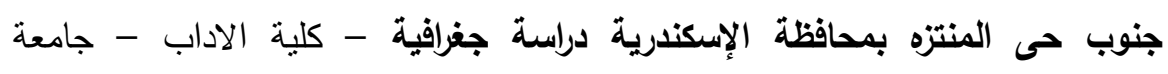

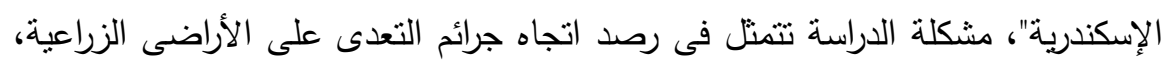

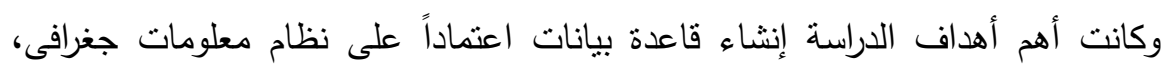

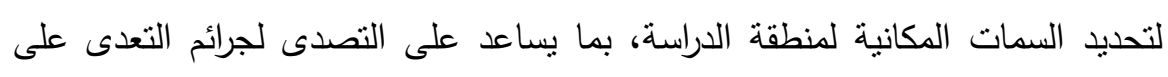

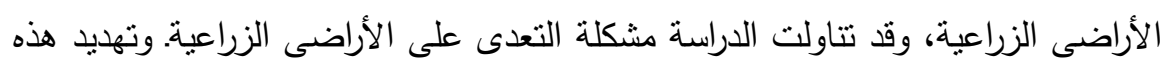

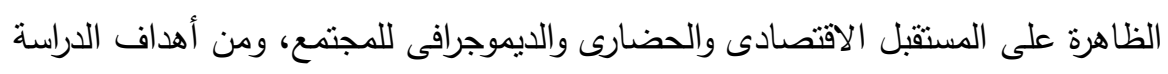

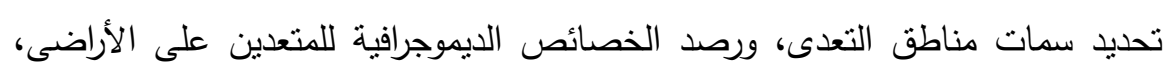

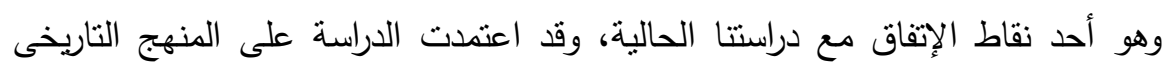


والمنهج الإقليمى ومن أدواتها تطبيقات نظم المعلومات الجغرافية، وانتهت الدراسة إلى أنه من أسباب انتشار جريمة التعدى على الأراضى ضعف ومن قدرة الدولة فى نطبيق القانون، وأوصت الدراسة بضرورة توفير آلية للمراقبة تسمح بمنع التعدى على الأراضى فئى، وتتثديد العقوبات على المتعدين وتقنين عمليات شق الطرق السريعة لربط التجمعات العمرانية المتتاثرة، والإشراف على أنشاء مجتمعات عمرانية زراعية بعيدة عن الكتلة الزراعية القديمة.

\section{الإطار المظظرى للدواهما}

$$
\text { استعرضت الدراسة المفاهيم الأساسية على النحو التالى: }
$$

البناء الاجتماعىSocial Structure: يقصد به مجموعة الأطر التتظيمية التى تحكم

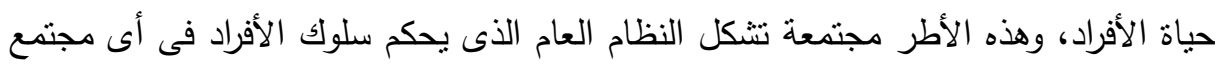

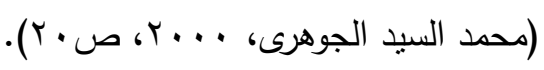

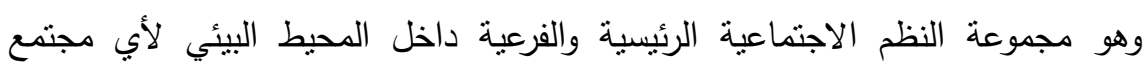

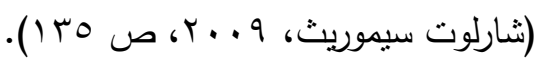

ويمكن تعريفه اجرائياً بأنه مجموعة العادات والتقاليد الموضوعة والموروثة التى تحكم حياة

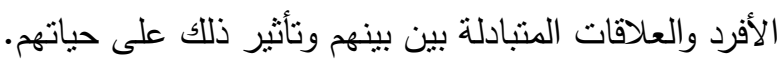
استخدامات الأراضي:Land use: يقصد به التوزيع المكانى لوظيفة الأرض (سكن -

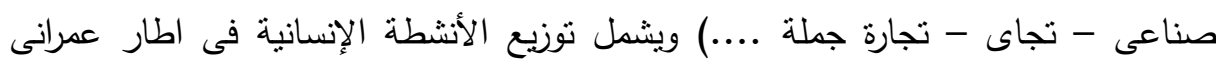
- (Frances, 1965, , p7-9)

كما عرفتها Helen بأنه وظيفة الأرض فى الوقت الراهن والغرض من استخداماتها،

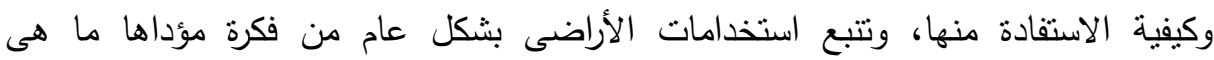
Helen ( احتباجاتتا وما هى طرق اشباعنا لهذه الاجتياجات فى ضوء الموارد المتاحة 
التنمية المستدامة :Sustainable Development: تعرف بأنها التتمية التى تلبى احتياجات الحاضر دون التاثير على قدرة الأجيال القادمة على تلبية احتياجاتهم (,p37Paul\& Marchenary1991,) كما عرفتها هيئة الأمم المتحدة بأنهاعملية تطوير شاملة للأرض بما تضمه من مجتمعات

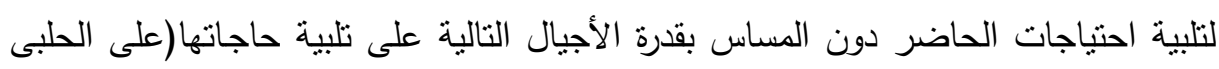

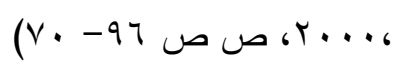

نظم المعلومات الجغرافية Geographical Information System: هي نمط تطبيقي لتكنولوجيا الحاسب الآلي بشقيهالأساسيين: البرامج(Software) والمكونات المادية

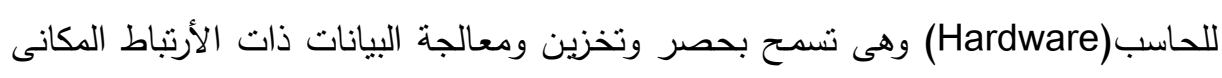

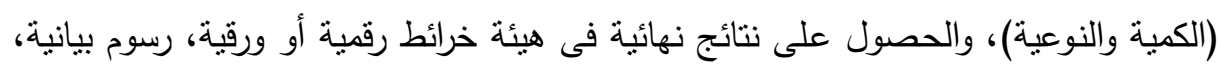
مجسمات، صور ، جداول أوتقارير علمية (2000 - George , P.S). تعرف مؤسسة إزرى ESRI, . 199، نظم المعلومات الجغرافية أنها مجمع متناسق يضم

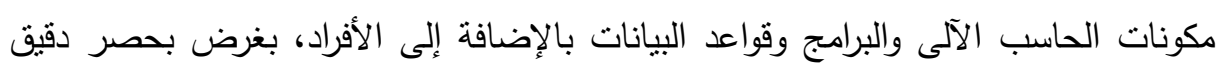

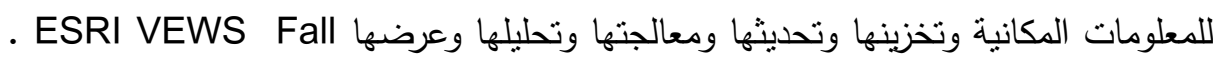
Status Report on ARC/GIS Data Models. r... ^

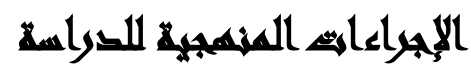

مناهج الدراسة: اعتمدت الدراسة على المناهج التالية :

• المنهج الأنثرويولوجى: استمدت الدراسة من هذا المنهج التعمق فى فهم مجتمع لاعن الدراسة، من خلال المعايثة التامة والملاحظة الدقيقة للسكان، والتعرف على أهم عاداتهم

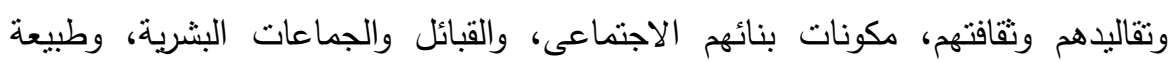

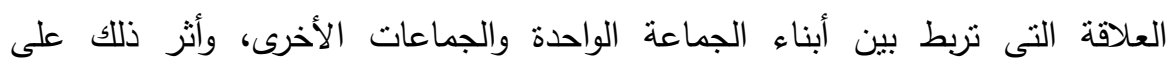
استخدامات الأراضى فى المحافظة. 
المنهج التاريخي: تتاولت الدراسة استخدامات الأراضى فى محافظة اسوان فى فترات

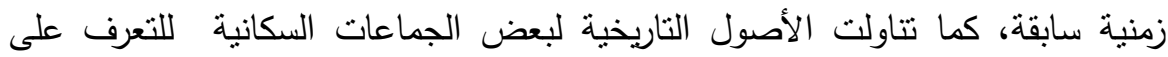

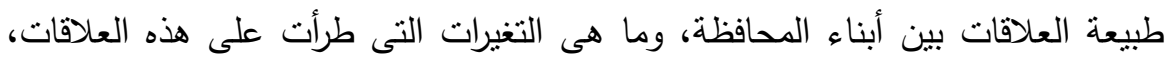

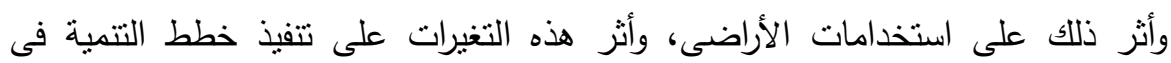

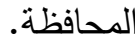

• الإسلوب الكمى: يساعد فى تحليل العلاقات بين خصائص السكان وأنماط استخدامات الأراضى، كما يساعد أيضاً فى تحليل العلاقات الكمية بين أنماط استخدامات الأراضى، للتوصل إلى أى الأنماط أكثر تركزاً عن غيرها، ومحاولة تفسير ذللك مع ربط هذه العلاقات بخصائص السكان الكمية والنوعية. • نظرية الدراسة::تبنت الدراسة نظرية التغبر الاجتماعى التقافى، ويقصد بها التغير المقصود وغير المقصود فى ثقافة الأفراد واسلوب ممارستهم لعاداتهم وتقاليدهم واستخدامهم للموارد المتاحة ببيئتهم، وينتج هذا التغير نتيجة الاحتكاك بنقافات مختلفة (همام بدراوى وشاكر فتحى، النربية المقارنة المنهج - الأساليب - النطبيقات، مجموعة النيل

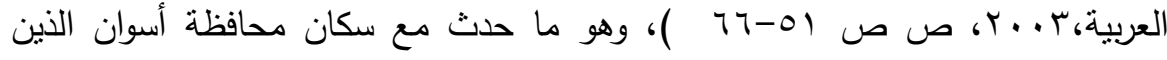
تعرضوا لطابع ثقافى مختلف من الوافدين إلى المحافظة خلال فترة بناء السد العالى، وما

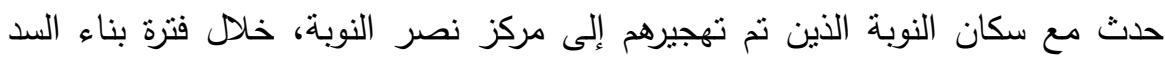
العالى، وقد ترتب عليه تغير فى البناء الاجتماعى لسكام محافظة اسوان فى بسقهم التقافى لهيه

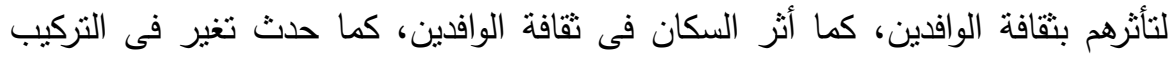

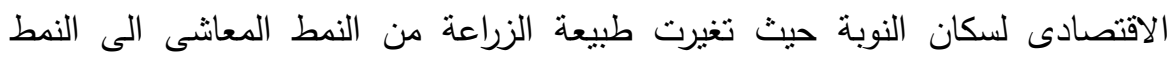

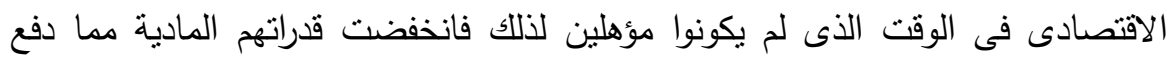

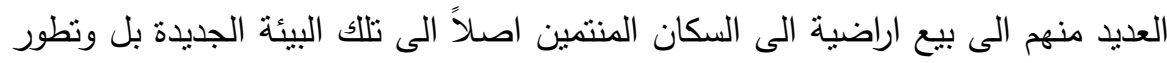

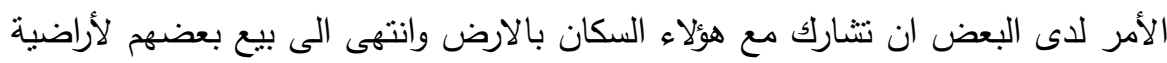

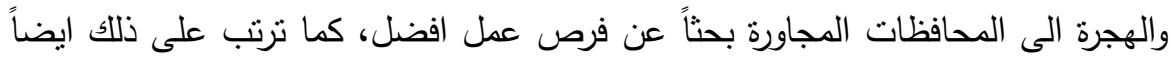
تغير فى تقافة الأسرة والأضرار للتخلى عن بعض العادات الموروثة مثل عادات اقامة

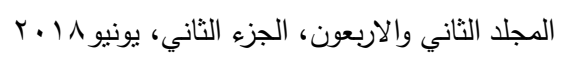


العريس فى بين اهل عروسته لمدة عام او عامين قبل الانتقال الى مقر اقامته الدائنة فى بيته او بين اهلة فانقرضت تلك العادة بفعل ضيق المسكن الجديد.

\section{أسوايت التوراسة}

المستح الميدانى: هي أداة لا غنى عنها لأى دارس فى مجال البيئة وخاصة المعتمدين على تقنية نظم المعلومات الجغرافية، حيث تقوم برصد الواقع الفعلى لإستخدامات

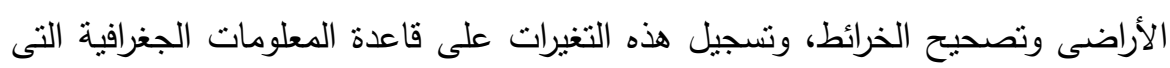
اعدتها الدراسة، كما تساعد فى رصد التجمعات البشرية بمكوناتهم وخصائصهم المختلفة. الملاحظة: أداة انثروبولوجية نساعد فى رصد التصرفات الفردية والجماعية أثثاء الأحداث المختلفة، وهو ما استفاد منه الطالب أثناء العمل الميدانى حيث لاحظ العادات والتقاليد

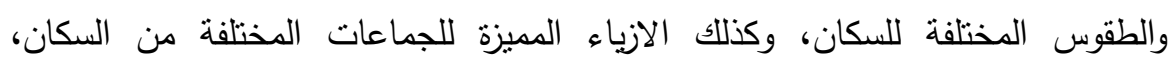
وتصرفات السكان فى المناسباتالمختلفة، وإجراءات جلسات العرف بالمحافظة.

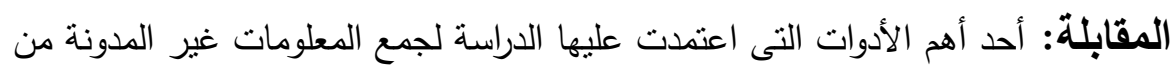

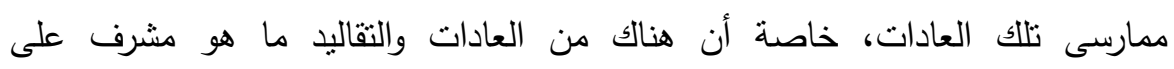
الإنقراض، مثل العادات المتبعة فى الزواج والدفن النى كانت سائدة بين السكان فى فترات

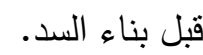

نظم المعلومات الجغرافي: عمدت إليها الدراسة لمعالجة الخرائط الورقية التى نم

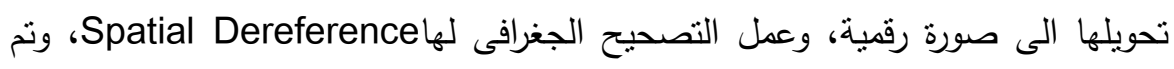
الربط بين الخصائص البيئية والخصائص الاجتماعية والاقتصادية لقاطنى هذه البيئات،

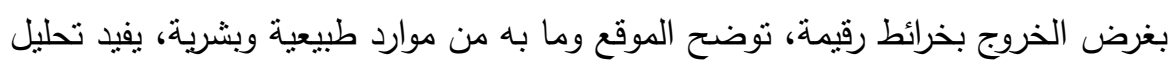
هذا الخرائط فى تفسير جانب من أثز البناء الاجتماعى للسكان بأنساقه على استخدامات الأراضى 


\section{عضوض القراسة}

\section{ترتكز الدراسة على ثلاثة أطر رئيسية هى:}

• الإطار المكانى: يشمل محافظة أسوان ثم التركيز على مركز أدفو كحالة تطبيقية.

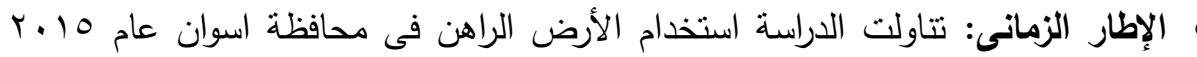
مع دراسة تطور استخدام الأرض بالمحافظة منذ ما قبل عام •919 اوفى المرحلة الثانية

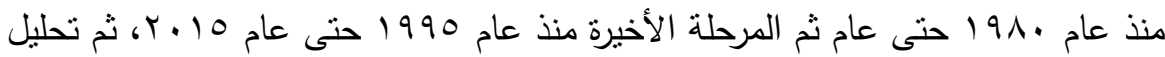

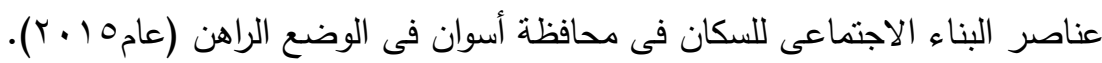

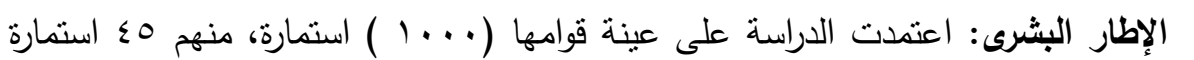

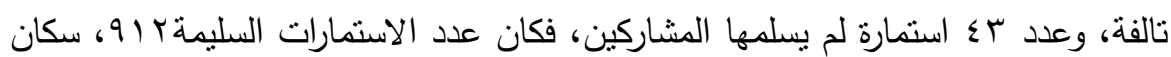
مركز أدفو، نم اختيارهم بطريقة عشوائية.

\section{أوراهت الصراسة}

قام الباحثون بإعداد دليل حالة عن عناصر البناء الاجتماعي للسكان ومتغيراته، وهى

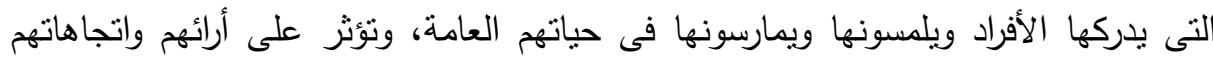

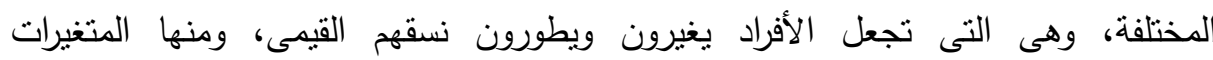
الاقتصادية والسياسية والقرارات الحكومية والهجرة. وقد تضمن دليل الحالة عدد(9 §) سؤال، منهم عدد (7) أسئلة اساسية عن أفراد عينة الدراسة وهى (السن - التعليم - النوع - طبيعة العمل - الحالة الاجتماعية - طبيعة المحلة

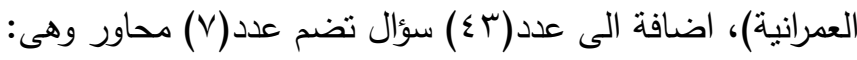

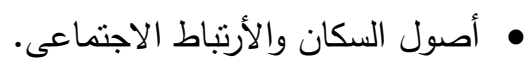
• تفاعل السكان مع البيئة فى منطقة الدراسة.

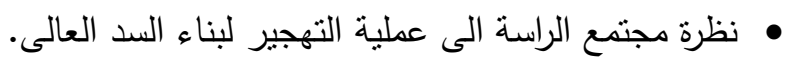
• المشروعات التتموية فى منطقة الدراسة . • نظرة السكان الى التعليم. 


$$
\text { • • رؤية النكان لقضية التعدى على الأراضى. }
$$

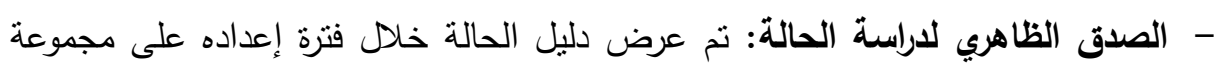

$$
\text { من الأساتذة المتخصصين فى علومالاجتماعوالجغرافيا. }
$$

- الصدق المنطقي(صدق التكوين): يهدف للحكم على الأبعاد التي سيتكون منها الاستبيان،

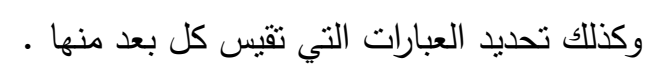

- ثبات الاستبيان بطريقة أعادة التطبيق : حيث نم إجراء ثبات الاستبيان بنطبيقه على ني

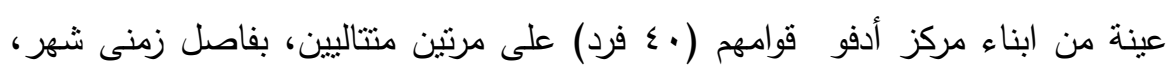

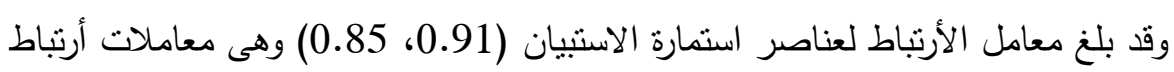

$$
\text { ذات دالة ومرتفعة. }
$$

- بلغ عدد الاستثمارات التى تم تصميمها( . . . (1)، قام الباحث بتوزيعها على ينة الدراسة

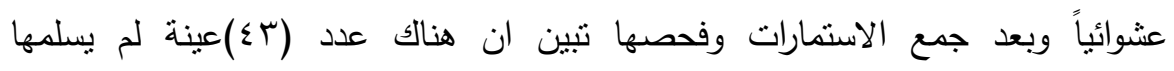

\begin{tabular}{|c|c|c|c|c|}
\hline \multirow{2}{*}{$\mathbf{R 2}$} & \multicolumn{2}{|c|}{ t. test } & \multirow{2}{*}{ المعلمات المقدرة } & \multirow{2}{*}{ المتغير المستقل } \\
\hline & مستوى المعنوية & القيمة & & \\
\hline \multirow{2}{*}{$\% 71,9$} & $* * \cdot, \cdot 1$ & $11,0 Y \varepsilon$ & $9, \varepsilon \cdot \varepsilon$ & الجزيء الثنابت \\
\hline & $* *, \cdot, 1$ & $\Gamma \wedge, \Sigma T r$ & $r, r \leqslant \Lambda$ & استخدامات الأراضى \\
\hline
\end{tabular}
المفحوصين، وعدد (0) استمارة تالفة لم يقم المفحوصين بالإجابة على جميع الأسئلة،

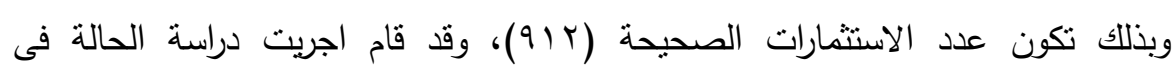

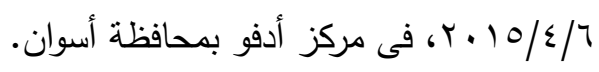

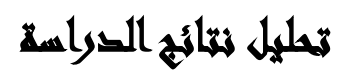

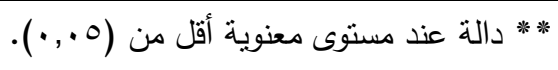

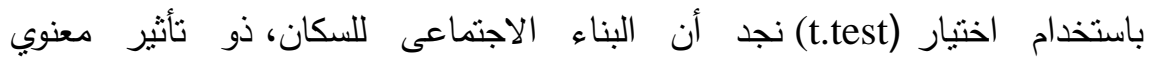

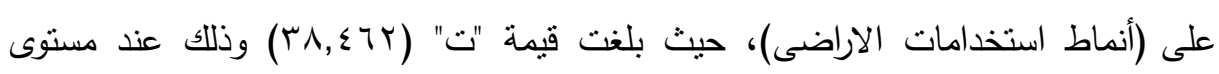

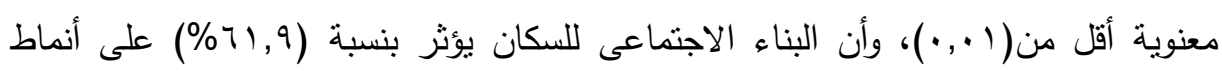

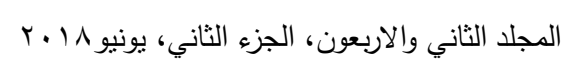


استخدامات الأراضي، ويوجد عوامل اخرى مثل القرارات الحكومية وتوجهات الدولة وبعض

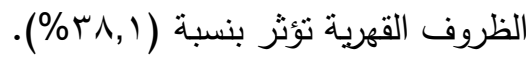
جدول رقم(ץ): تأثنر البناء الاجتماعى للسكان على العوامل الاقتصادية للدولة

\begin{tabular}{|c|c|c|c|c|}
\hline \multirow[b]{2}{*}{$\mathbf{R 2}$} & \multicolumn{2}{|c|}{ t. test } & \multirow{2}{*}{ المعلمات المقدرة } & \multirow[b]{2}{*}{ المتغير المستقل } \\
\hline & مستوى المعنويـة & القيمة & & \\
\hline \multirow{2}{*}{$\% \leq \vee, \vee$} & $* * \cdot, \cdot, 1$ & A,YTY & $9, \cdot 1 V$ & الجزي الثابت \\
\hline & $* *,, \cdot 1$ & $Y \wedge, \Lambda \cdot \Lambda$ & $\varepsilon, \varepsilon \circ \wedge$ & الاقتصادية للدولة \\
\hline
\end{tabular}
*** دالة عند مستوى معنوية أقل من (0. . .•).

باستخدام اختيار (T.Test) نجد أن البناء الاجتماعي للسكان، ذو نتأنثير معنوي

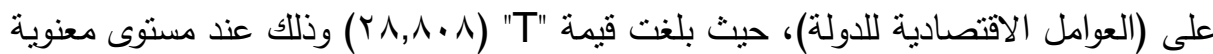
أقل من (0., (·)، كما نجد أن معامل التحديد (R2)، يوضح أن البناء الاجتماعي للسكان

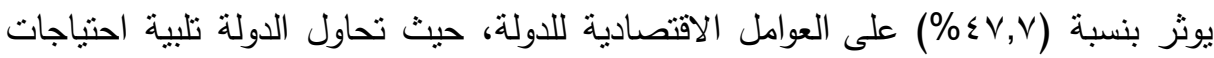

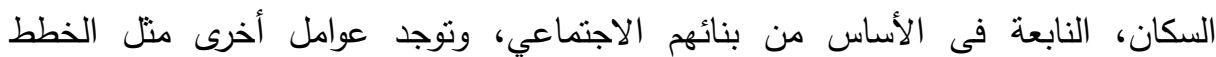
الإستراتيجية والظروف الاقتصادية والسياسية للدولة، وهذه العوامل تؤثر بنسبة r, ro \% . جدول رقم(r): تأثنير فعالية استخدامات الأراضى على تتفيذ خطط التتمية المستدامة

\begin{tabular}{|c|c|c|c|c|}
\hline \multirow{2}{*}{ R2 } & \multicolumn{2}{|c|}{ t. test } & \multirow{2}{*}{ المعلمات المقرة } & \multirow{2}{*}{ المتغير المستقل } \\
\hline & مستوي المعنوية & القيمة & & \\
\hline \multirow{2}{*}{$\% \wedge \neg, \wedge$} & $* *,,+1$ & TI,VKY & $10, \Lambda \Gamma V$ & الجزء الثابت \\
\hline & $* * \cdot, \cdot 1$ & $V V, Y Y \varepsilon$ & T, זNI & خطط التتمية ألمستدامة \\
\hline
\end{tabular}

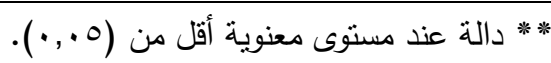

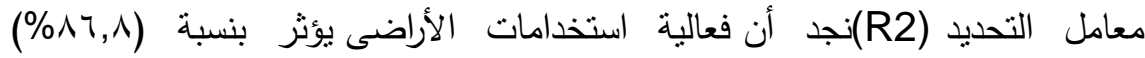
على تتفيذ خطط التتمية المستدامة،وتوجد عوامل أخرى مثل العوامل الاقتصادية والقرارات

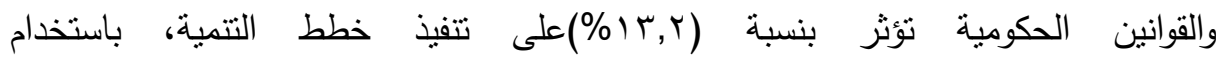

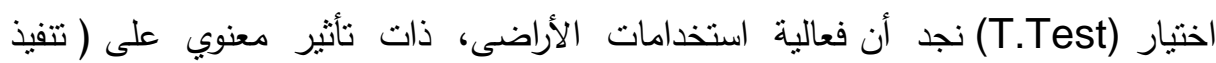

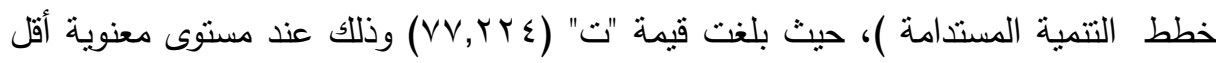
من (*). (*) 
جدول رقم(ع): تأثنر الهجرة على البناء الاجنماعى

\begin{tabular}{|c|c|c|c|c|}
\hline \multirow{2}{*}{$\mathbf{R 2}$} & \multicolumn{2}{|c|}{ t. test } & \multirow{2}{*}{ المعلمات المقدرة } & \multirow{2}{*}{ المتغير المستقل } \\
\hline & مستوى المعنوية & القيمة & & \\
\hline \multirow{2}{*}{$\% 90,1$} & $* *,, \cdot 1$ & $\cdot, \leqslant \leqslant$. & $\cdot, 1$ Yo & الجزء الثابت \\
\hline & ***, ,, 1 & $I T \varepsilon, V Y T$ & $r, \cdot \leq \varepsilon \cdot$ & البناء الاجتماعى \\
\hline
\end{tabular}

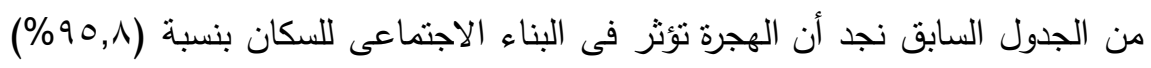

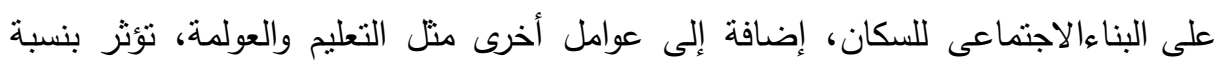
(T, ؟ \%) ) وباستخدام اختيار (T.Test) نجد أن فعالية الهجرة، ذات تأثنير معنوي على (البناء

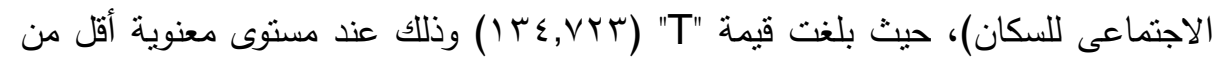
$\cdot(\cdot, \cdot 0)$

\section{مناهي}

• تعانى المحافظة من عجز فى خدمات التعليم العالى، الفندقى والسياحى والزراعى، حيث

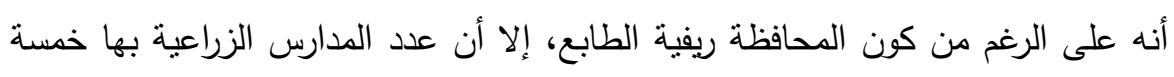

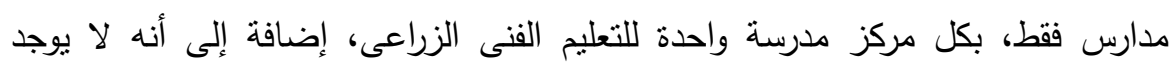

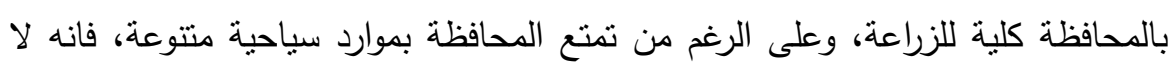
يوجد بها كلية للسياحة والفنادق وذللك لا كلية للأثنار . توجد علاقة عكسية بين مستوى التعليم والتعدى على الأراضى املاكى الدولة.

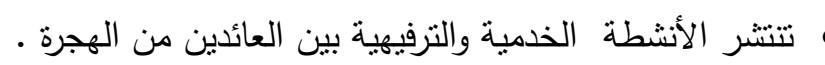

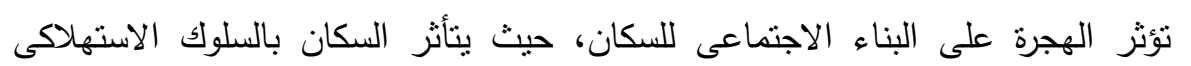

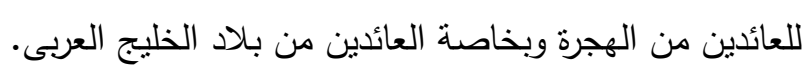

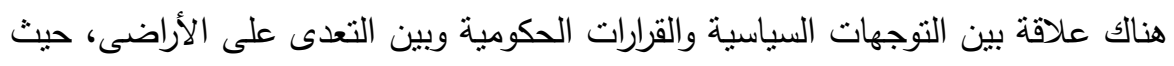
أن شق الطرق أو أنشاء المدن، يؤدى إلى تغيير الوضع الأقتصادى بالمنطقة، ويتجه السكان إلى تغيير أنشطة الأراضى الزراعية الى أنشطة أخرى غير زراعية. 
• يرى السكان أهمية كبيرة للنشاط الصناعى، إلا أنهم يحجمون عن الاستثمار فيه، نظرأ

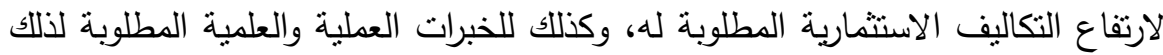
النشاط، لذا يقبلون على ممارسة الأنثطة الخدمية والتزفيهية. • يرى السكان بالمحافظة أنه على الدولة التوسع فى الأنشطة الصناعية، وتدعيم التعليم الفنى الصناعى، وربطة بمنطلبات سوق العمل. • تمتلك محافظة أسوان مقومات صناعية قائمة على الخامات الزراعية والتعدينية، مثل خامات صناعة الأسمنت والفوسفات والرخام والخامات المعدنية فلزية ولا فلزية، إضافة إلى الى توافر مصادر الطاقة، كما تمتلك المحافظة شبكة من الطرق تصلها بالمحافظات المجاورة يمكن التعويل علها في رسم خطط التتمية. • بمكن للاولة سد احتباجاتها من الورق ومن الخشب الحبيبى من خلال إنشاء مصانع جديدة بالمحافظة إعنماداً على الخامات المحلية المنوافرة والايدى العاملة منخفضة التكاليف. لمان.

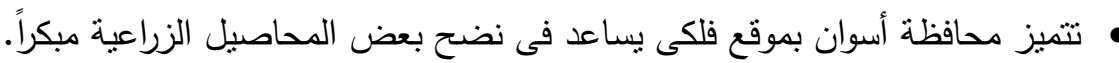

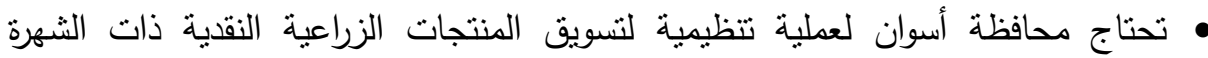
العالمية مثل الكركادية ونخيل البلح.

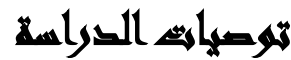

من خلال النتائج السابقة تقدم الاراسة بعض التوصيات كما يلى:

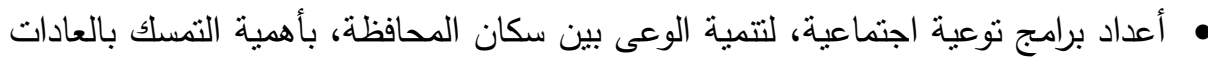

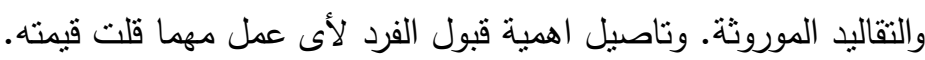

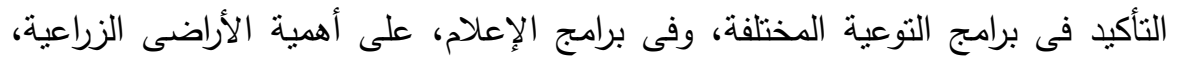

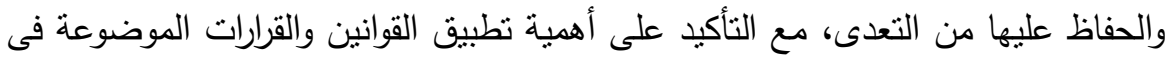
هذا الثنأن. • التأكيد على أهمية أراضى أملاد الدولة، فى خطط التتمية الموضوعة، وأن عمليات التعدى على هذه الأراضى، تعيق تتفيذ تلك الخطط. 
إعطاء الدولة أولوية اكبر للتعمق فى دراسة دراسة البناء الاجتماعى للسكان، وخاصة فى

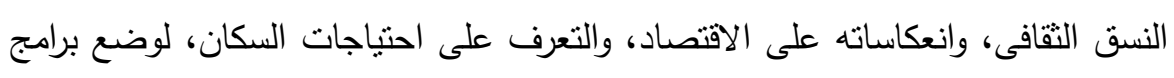
لسد تلك الاحتياجات.

تعزيز النظرة الاجتماعية إلى التعليم الفنى نظام الثلاث سنوات من خلد برامج توعية مختلفة المصادر وعلى فترات زمنية طويلة على ان تخاطب جميع طبقات المجتمع.

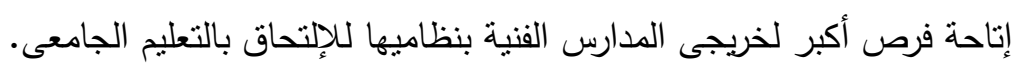
الربط بين مناهج التعليم الفنى بأنواعة ومنطلبات سوق العمل لمساعدة خريجى تلكي

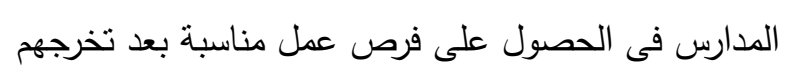

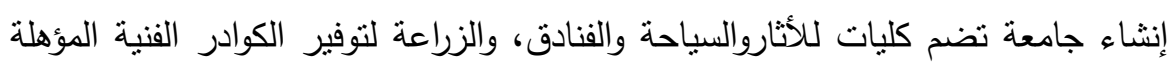
للتعامل مع المقومات المتتوعة بالمحافظة. التاكيد على تضمين مفاهيم التتمية المستدامة وادارة البيئة ضمن المناهج التعليمية بمراحلها المختلفة تفعيل دور مراكز نظم المعلومات الجغرافية فى اعمال المراقبة المتابعة للاراضى وتضمينها فى ادوات اتخاذ القرارات التأكبد على تطبيق قوانينمواجهة التعدى على الأراضى، سواء من خلال تقنين وضع اليد

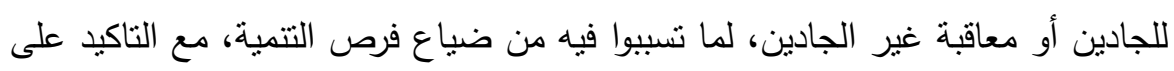
حق الدولة فى جميع الحالات بالاحتفاظ باراضيها وفقاُ لخطط التتمية. تزويد مراكز المحافظة وبخاصة مركز نصر النوبة، بمراكز تدريب على الأعمال المهنية، بناء على متطلبات سوق العمل. إنشاء مصانع لإنتاج الورق والخشب بالاعنماد على الخامات المتمنلة فى محلفات صناعة قصب السكر . • إنشاء مركز تسويق للحاصلات الزراعية، للاستفادة من ميزة النضج المبكر لبعض المحاصيل. 


\section{المرالئ}

سمير نعيم أحمد(Y Y. Y): أهل مصر عبقرية البقاء والاستمرار، كلبة الاداب، جامعة عين

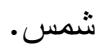

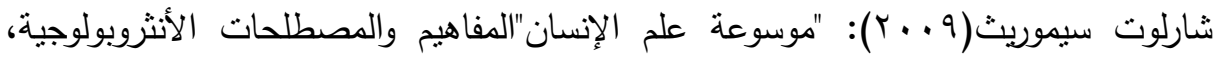

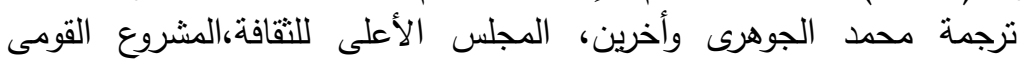

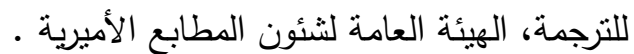

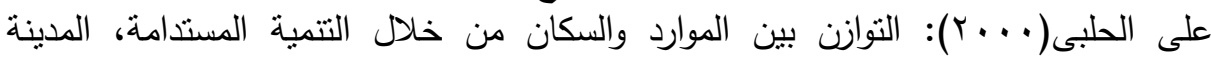
العربية.

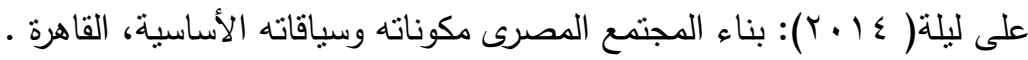

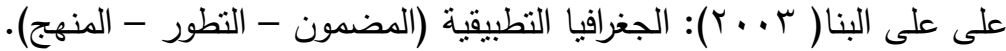

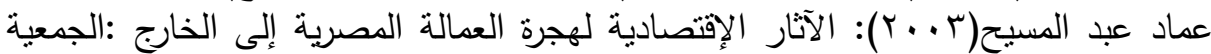

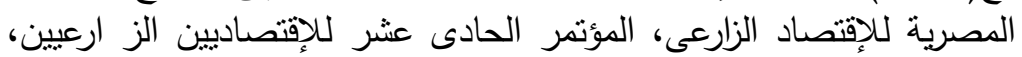

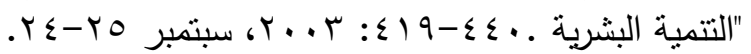

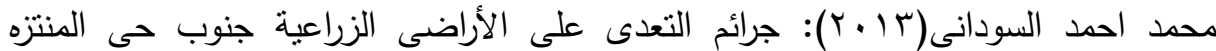

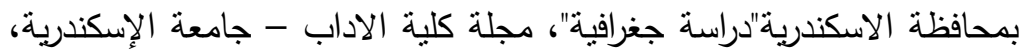

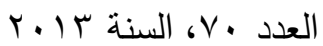

محد السيد الجوهرى( . . r): المدخل إلى على الاجتماع، سلسلة علم الاجتماع المعاصر،

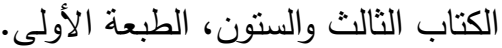

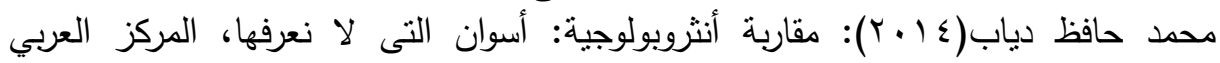
لابحوث والدراسات

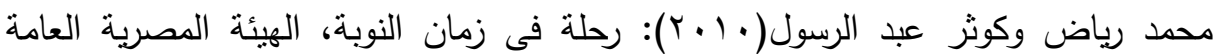
للكتاب، القاهرة

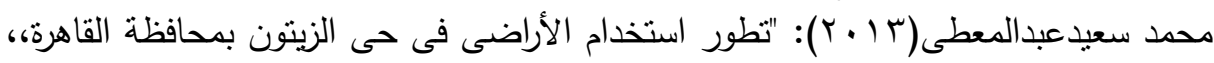

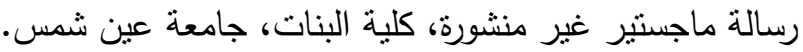

محمد عاطف غيث(999 (1)): قاموس علم الاجتماع، دار المعارف الجامعية،الإسكندرية.

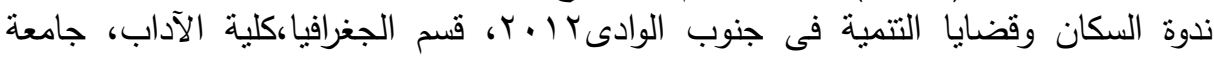

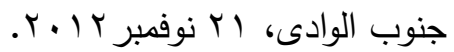

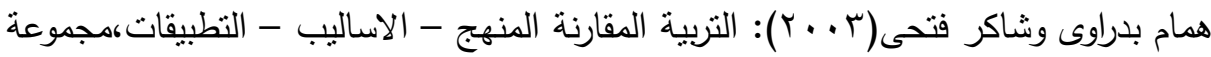

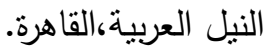

ESRI VEWS ( Fall 2008) Status Report on ARC/GIS Data Models.

Frances 1965, .Sturart Chapin, urban land use Planing. 
George, P.S (2000); Management Information Systems , Prentice Hall.

Helen Briassoulis(2003): Analysis of Land use change theoretical and modeling approaches.

Jan Bojo nda(1992): Unemo, environmental and development an economic approach Boston.

Mckelvey (March 3,1849 ), Land Use and Land Cover Classification System forUse with Remote Sensor Data, Geological Survey Professional Paper, U.S. Departmentof the Interior, University of Illinois.

Paul\& marc henary1991, poverty,progress anddevelopment.

Ray M.Northan(1979) Urban Geography. 


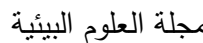

معهد الدراسات والبحوث البيئية - جامعة عين شمس لمس لمس

\title{
IMPACT OF SOCIAL CONSTRUCTION ON LAND
}

USE AND DEVELOPMENT IN PROVINCE

ASWAN USING GEOGRAPHIC INFORMATION

SYSTEMS - STUDY OF ANTHROPOLOGY

Awad, M. I. ${ }^{(1)}$; Abu Nile, Naja, A. ${ }^{(2)}$ and Abdul Sattar, A. I.

1) Institute of Environmental Studies \& Research, Ain Shams University 2) Faculty of Arts, Ain Shams University

\begin{abstract}
The social construction of the population is a cornerstone in the treatment of man with the land, and the more we can understand the components of social construction of the population, and must understand the components of this building, to support the positive and negative evaluation of it, the study aims to address the impact of social construction of the population on patterns of land use, Such as the study of the social construction elements of the population in Aswan Governorate, the changes that have taken place, the reasons for this change, and the study of the effect of the social construction of the population on the patterns of land use in Aswan Governorate.

The study was based on a sample of (1000) single, 45 of which were damaged, and 43 were not delivered by the participants. The number of valid forms was 912, and the student used the anthropological approach, the historical approach, the direct interview.

The study showed that there is an inverse relationship between the level of education and the encroachment on the land. The distribution of urban shops in the governorate was affected in part by the nature of the social structure of the population. The urban shops spread in the form of small contiguous spots, some of which belong in close relations, to preserve the privacy of the social life of the population. The study indicates that there are differences between the encroachment on the
\end{abstract}

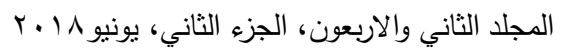


agricultural lands and the lands of the state's private lands in terms of area and activity and the nature of the transgressor itself. The encroachment is dominant and influential, and the social construction of the population has been influenced by the immigration factor, Economic development of the country,

The study shows that immigrants of low scientific backgrounds are active in recreational and service activities and refrain from industrial activities. The governorate suffers from a quantitative and qualitative shortage in agricultural education. The center also has no colleges (for agriculture, tourism and hotels, archeology) Educational and labor market requirements. Based on the findings of the study and its findings, the study presented recommendations including

- Dissemination of awareness programs about the importance of protecting the land from encroachment and its impact on development plans.

- Establishment of colleges (for tourism and hotels - the effects - for agriculture), and interest in the dissemination and development of technical schools.

- Establishment of marketing entities for agricultural products to benefit from the early maturity of crops.

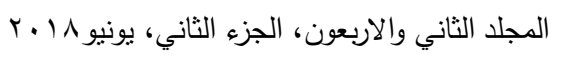

